\title{
Leber's optic neuropathy: clinical and visual evoked response studies in asymptomatic and symptomatic members of a 4-generation family
}

\author{
I. R. LiVingSTONE, F. L. MASTAGLiA, J. W. HOWE, ANd G. E. S. AHERNE \\ From the Muscular Dystrophy Group Research Laboratories, Regional Neurological Centre, Newcastle \\ General Hospital, Newcastle upon Tyne; the University Department of Ophthalmology, University of \\ Newcastle upon Tyne, Royal Victoria Infirmary, Newcastle upon Tyne; and the University Department of \\ Human Genetics, University of Newcastle upon Tyne, Royal Victoria Infirmary, Newcastle upon Tyne
}

SUMMARY A clinical and neuro-ophthalmological examination using tests of visual acuity, quantitative visual field analysis, tests of colour discrimination, ophthalmoscopy, and pattern visual evoked responses was performed on 2 symptomatic and 16 asymptomatic members of a family with Leber's optic neuropathy. The visual evoked responses were abnormal in the 2 clinically affected males and in 1 asymptomatic male. Tests of colour discrimination with Ishihara plates, the Farnsworth-Munsell 100 hue test, and the Nagel anomaloscope revealed abnormalities in 8 asymptomatic family members, with the Farnsworth-Munsell test proving to be the most sensitive to mild abnormalities of colour discrimination. The occurrence of detectable neuro-ophthalmological abnormalities within this family is in keeping with the expected pattern of transmission of Leber's optic neuropathy. The significance of detection of presymptomatically affected cases and asymptomatic carriers is discussed.

A familial type of optic neuropathy first described by Theodore Leber in $1871^{1}$ effects predominantly young males and causes an acute or subacute failure of vision affecting both eyes, though not usually simultaneously, leading eventually to optic atrophy.

Leber's optic neuropathy is inherited in a unique fashion. The pattern of inheritance, first thought to be an X-linked disorder, does not conform to Mendelian principles. ${ }^{2-4}$ Various hypotheses put forward as alternatives to Mendelian inheritance include the vertical transmission of some infectious agent such as a slow virus ${ }^{5}$ or similar agent through the female parent via the maternal ooplasm ${ }^{7}$ or transplacentally. ${ }^{6} 9$

The finding of neuro-ophthalmic and visual evoked response abnormalities in some asymptomatic members of a family with Leber's optic neuropathy ${ }^{10}$ suggests that the detection of asymptomatic carriers and presymptomatically affected cases is possible.

The present study seeks to define the nature and incidence of neuro-ophthalmological abnormalities

Correspondence to Mr J. W. Howe, Department of Ophthalmology, Royal Victoria Infirmary, Newcastle upon Tyne.

*Present address: University Department of Medicine, Queen Elizabeth II Medical Centre, Nedlands, W.A. 6009, Australia. in both symptomatic and asymptomatic members of a family with Leber's atrophy by recording the visual evoked responses and carrying out a clinical neuro-ophthalmological examination, with detailed testing of colour vision.

\section{Patients and methods}

We studied 2 affected males and 16 asymptomatic members in a 4-generation family with Leber's optic atrophy (Fig. 1). Hospital records on 2 deceased affected cases $\left(\mathrm{II}_{3}, \mathrm{III}_{5}\right)$ are consistent with the diagnosis of Leber's optic atrophy in that both patients presented at the age of 21 years with a rapid sequential irreversible visual loss in both eyes leading to optic atrophy. No female in this family was known to have had visual loss, and none of the apparently healthy members had any visual symptoms which were not corrected by simple refraction. Of the 2 affected brothers studied (cases $\mathrm{IV}_{1}, \mathrm{IV}_{4}$ ) the elder presented at the age of 20 years with failing vision in the right eye followed 1 month later by similar symptoms involving the left eye. Examination at that time showed bilateral central scotomata and disc swelling, which was noted to lead on to blue-grey atrophy of both discs 6 months later. The 


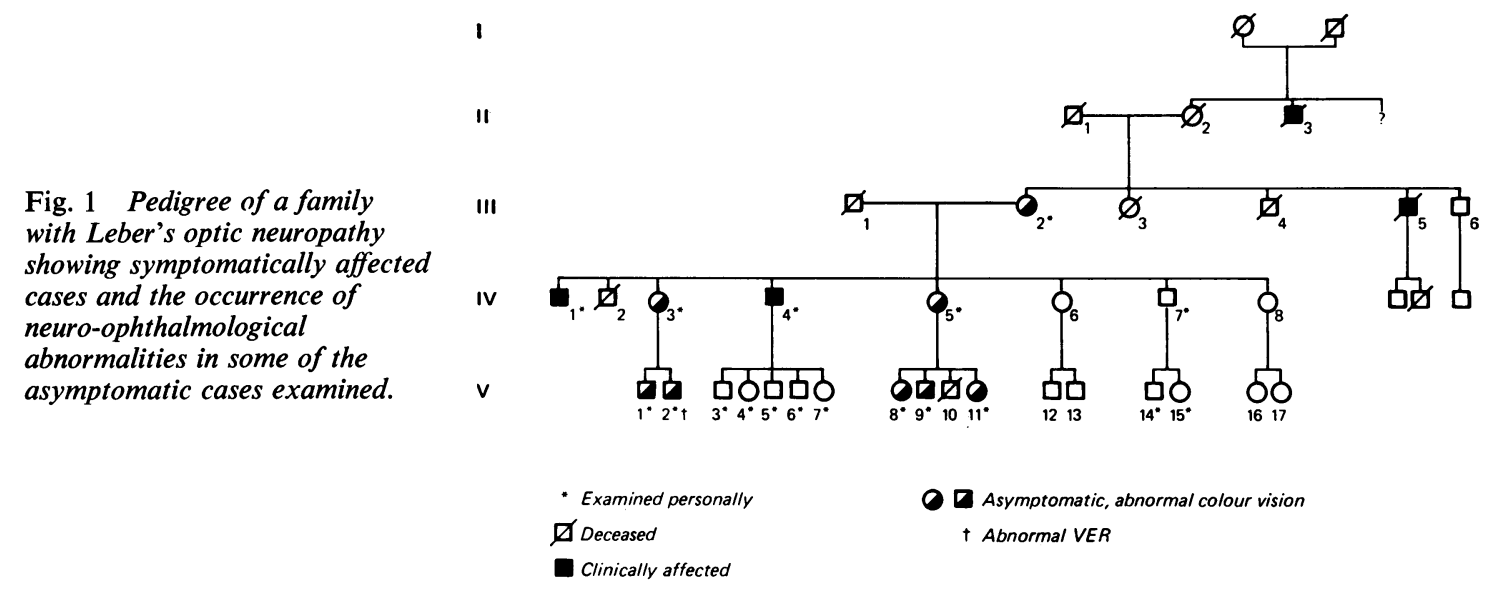

younger brother $\left(\mathrm{IV}_{4}\right)$ had a similar presentation at the age of 21 years with acute visual failure beginning in the right eye followed 6 weeks later by similar symptoms in the left eye, leading irreversibly to optic atrophy.

\section{EXAMINATION}

All patients in this study underwent a neuroophthalmological examination which included measurement of visual acuity (Snellen charts), quantitative perimetry by the Friedman field analyser, and detailed testing of colour vision with Ishihara plates, the Farnsworth-Munsell (F-M) 100 hue test, and the Nagel anomaloscope. The appearances of the retinal blood vessels and optic discs were noted in each patient. An abnormality on reading the Ishihara plates was noted if 3 or more mistakes were made on presentation of 25 colour plates to each eye The F-M 100 hue test for colour discrimination was conducted under standardised lighting by the recommended technique. ${ }^{11}$ Abnormalities on this test were evaluated according to the criteria of Verreist. ${ }^{12}$ A Nagel anomaloscope model 1 was used to test the patient's ability to achieve Rayleigh's match: red $(570 \mathrm{~nm})+$ green $(546 \mathrm{~nm})=$ yellow $(589.3 \mathrm{~nm})$. We determined an anomaly quotient (AQ) by comparing the subject's performance with that of an unrelated control subject, using the formula based on the relative mixing of green and red to achieve the yellow match:

$\begin{gathered}\text { Relative width of green slit } \\ \text { (test subject) }\end{gathered}$
$\begin{gathered}\text { Relative width of red slit } \\ \text { (test subject) }\end{gathered}$$\frac{\begin{array}{c}\text { Relative width of green slit } \\ \text { (control subject) }\end{array}}{\begin{array}{c}\text { Relative width of red slit } \\ \text { (control subject) }\end{array}}$

A value of 1.0 is accepted as normal with a range of 0.95 to 1.05 (mean $\pm 2.5 \mathrm{SD}$ ) obtained on testing 12 healthy control subjects.

Visual evoked responses (VER) were recorded by using $\mathrm{Ag} / \mathrm{Ag} \mathrm{Cl}_{2}$ electroencaphalograph electrodes placed according to the international 10-20 system. The active electrode was at $\mathrm{Oz}$ and the reference electrode was at $\mathrm{Cz}$ (vertex), and an earth electrode was placed on the forehead. Pattern visual stimulation was provided by a television pattern generator. ${ }^{13}$ The frequency of reversal of the frame locked pattern was $2 \mathrm{~Hz}$, and the transition time for pattern reversal was $20 \mathrm{~ms}$. At the viewing distance used ( 1.7 metres) the screen subtended angles of $17^{\circ} 10^{\prime}$ (horizontal) and $13^{\circ}$ (vertical) at the eye, and each check had a visual subtense of $50^{\prime}$. Contrast was set to maximum and the luminance was kept constant. Occipital responses were averaged by a Medelec MS6 polygraph triggered by each pattern reversal. The average response to 128 reversals was written out on a Phillips PM8041 X-Y recorder. Responses from each eye were obtained to whole-field stimulation. The subjects were requested to fixate on a $5 \mathrm{~mm}$ central spot on the television screen, and those with refractive errors wore corrective lenses.

The latencies of the major positive component (P2 or P100) and of the negative peaks (N1, N2) preceding and following the P2 peak were determined. The latency difference between the 2 negative peaks was used as the index of temporal dispersion, and the amplitude was defined as the difference in potential between the $\mathrm{N} 1$ and $\mathrm{N} 2$ peaks. In addition the P2 latency difference between the 2 eyes was calculated. All these parameters were compared to normal values obtained from 32 healthy subjects by taking the mean \pm 2.5 standard deviations as the upper and lower limits of normal for each of the parameters.

\section{Results}

\section{AFFECTED INDIVIDUALS}

The two clinically affected males (cases $\mathrm{IV}_{1}$ and $\mathrm{IV}_{4}$ ) both had markedly reduced visual acuities of 
Table 1 Summary of the neuro-ophthalmic and visual evoked response findings in both symptomatic and asymptomatic members of a family with Leber's optic neuropathy

\begin{tabular}{|c|c|c|c|c|c|c|c|c|c|c|}
\hline \multirow{2}{*}{ Patient } & \multirow{2}{*}{ Age } & \multicolumn{2}{|c|}{ Visual acuity** } & \multicolumn{3}{|c|}{ Colour discrimination } & \multicolumn{2}{|l|}{$V E R$} & \multicolumn{2}{|l|}{ Fundi } \\
\hline & & $R$ & $L$ & $\begin{array}{l}\text { Ishihara } \\
\text { plate } \dagger\end{array}$ & $\begin{array}{l}\text { Anomaloscope } * * * \dagger \\
\text { (anomaly quotient) }\end{array}$ & $\begin{array}{l}F-M 100 \text { hue test } \dagger \\
\text { (total error score) }\end{array}$ & $R$ & $L$ & $R$ & $L$ \\
\hline $\mathrm{III}_{2}$ & 66 & $6 / 9$ & $6 / 6$ & Abn & $1 \cdot 180$ & $\begin{array}{l}198^{*} \\
\text { Poor discrimination }\end{array}$ & $\mathbf{N}$ & $\mathbf{N}$ & $\begin{array}{l}\text { Ves } \\
\text { tort }\end{array}$ & sity \\
\hline $\mathrm{IV}_{1}$ & 47 & $6 / 60$ & $6 / 60$ & - & - & - & Flat & Flat & Atr & Atr \\
\hline $\mathrm{IV}_{\mathbf{3}}$ & 42 & $6 / 9$ & $6 / 9$ & $\mathbf{N}$ & - & $\begin{array}{l}143^{*} \\
\text { Poor discrimination }\end{array}$ & $\mathbf{N}$ & $\mathbf{N}$ & $\mathbf{N}$ & $\mathbf{N}$ \\
\hline IV، & 38 & $6 / 60$ & $6 / 60$ & - & - & - & Flat & Flat & Atr & Atr \\
\hline$I_{5}$ & 36 & $6 / 5$ & $6 / 6$ & $\mathbf{N}$ & 1.00 & $\begin{array}{l}81 \\
\text { Red-green axis }\end{array}$ & $\mathbf{N}$ & $\mathbf{N}$ & $\mathbf{N}$ & $\mathbf{N}$ \\
\hline$I_{7}$ & 32 & $6 / 6$ & $6 / 6$ & $\mathbf{N}$ & 1.00 & $\begin{array}{l}54 \\
\text { No axis }\end{array}$ & $\mathbf{N}$ & $\mathbf{N}$ & $\mathbf{N}$ & $\mathbf{N}$ \\
\hline $\mathrm{V}_{1}$ & 21 & $6 / 5$ & $6 / 5$ & Abn & $1 \cdot 317$ & $\begin{array}{l}116^{*} \\
\text { Peak at blue-green }\end{array}$ & $\mathbf{N}$ & $\mathbf{N}$ & $\mathbf{N}$ & $\mathbf{N}$ \\
\hline $\mathbf{V}_{2}$ & 18 & $6 / 5$ & $6 / 5$ & $\mathbf{N}$ & $1 \cdot 180$ & $\begin{array}{l}49 \\
\text { Red-green axis }\end{array}$ & Abn & Abn & $\mathbf{N}$ & $\mathbf{N}$ \\
\hline $\mathbf{V}_{3}$ & 17 & $6 / 5$ & $6 / 5$ & $\mathbf{N}$ & 1.00 & $\begin{array}{l}30 \\
\text { No axis }\end{array}$ & $\mathbf{N}$ & $\mathbf{N}$ & $\mathbf{N}$ & $\mathbf{N}$ \\
\hline V. & 13 & $6 / 5$ & $6 / 5$ & $\mathbf{N}$ & 1.00 & $\begin{array}{l}32 \\
\text { No axis }\end{array}$ & $\mathbf{N}$ & $\mathbf{N}$ & $\mathbf{N}$ & $\mathbf{N}$ \\
\hline $\mathbf{V}_{\mathbf{s}}$ & 12 & $6 / 6$ & $6 / 9$ & $\mathbf{N}$ & 0.95 & $\begin{array}{l}24 \\
\text { No axis }\end{array}$ & $\mathbf{N}$ & $\mathbf{N}$ & $\mathbf{N}$ & $\mathbf{N}$ \\
\hline $\mathbf{V}_{6}$ & 11 & $6 / 9$ & $6 / 6$ & $\mathbf{N}$ & 1.00 & $\begin{array}{l}56 \\
\text { No axis }\end{array}$ & $\mathbf{N}$ & $\mathbf{N}$ & $\mathbf{N}$ & $\mathbf{N}$ \\
\hline $\mathrm{V}_{2}$ & 8 & $6 / 9$ & $6 / 6$ & $\mathbf{N}$ & Not tested & Not tested & $\mathbf{N}$ & $\mathbf{N}$ & $\mathbf{N}$ & $\mathbf{N}$ \\
\hline$V_{8}$ & 17 & $6 / 6$ & $6 / 6$ & $\mathbf{N}$ & $1 \cdot 247$ & $\begin{array}{l}222^{*} \\
\text { Poor discrimination }\end{array}$ & $\mathbf{N}$ & $\mathbf{N}$ & $\mathbf{N}$ & $\mathbf{N}$ \\
\hline $\mathrm{V}_{9}$ & 13 & $6 / 6$ & $6 / 6$ & $\mathbf{N}$ & 1.057 & $\begin{array}{l}164^{*} \\
\text { Poor discrimination }\end{array}$ & $\mathbf{N}$ & $\mathbf{N}$ & $\mathbf{N}$ & $\mathbf{N}$ \\
\hline$V_{11}$ & 12 & $6 / 5$ & $6 / 5$ & $\mathbf{N}$ & 1.057 & $\begin{array}{l}170^{*} \\
\text { Poor discrimination }\end{array}$ & $\mathbf{N}$ & $\mathbf{N}$ & $\begin{array}{l}\text { Temporal } \\
\text { pallor }\end{array}$ & $\begin{array}{l}\text { Temporal } \\
\text { pallor }\end{array}$ \\
\hline$V_{14}$ & 9 & $6 / 5$ & $6 / 5$ & Not tested & Not tested & Not tested & $\mathbf{N}$ & $\mathbf{N}$ & $\mathbf{N}$ & $\mathbf{N}$ \\
\hline$V_{15}$ & 6 & $6 / 5$ & $6 / 5$ & Not tested & Not tested & Not tested & $\mathbf{N}$ & $\mathbf{N}$ & $\mathbf{N}$ & $\mathbf{N}$ \\
\hline
\end{tabular}

*Error score abnormal for respective age group. **Snellen chart. ***Normal range 0.95-1·05. †Values are given for the right eye only. No significant difference was obtained by testing the left eye. $\mathbf{N}=$ normal. Abn $=$ abnormal. Atr $=$ optic atrophy.

6/60 in each eye and optic atrophy (Table 1). Quantitative perimetry demonstrated bilateral central scotomata. Colour discrimination and visual acuity were so poor that tests of colour vision could not be performed. No recognisable component was present in the visual evoked responses from either eye in these 2 patients. General neurological examination revealed no abnormal signs.

DEFINITE CARRIER

On the basis of the pedigree only 1 person $\left(\mathrm{II}_{2}\right)$ who was examined could be positively identified as being a definite carrier. She had no visual symptoms and no abnormal signs on general neurological examination. Ophthalmoscopy, however, revealed that though disc appearances were normal there was an increase in the tortuosity of the small retinal vessels in each eye. This patient made a significant number of mistakes on the Ishihara plates with each eye, and her anomaly quotient of 1.18 indicated a moderate deuteranomalous (green deficient) match. Her F-M 100 hue test was consistently abnormal on repeated testing, with an abnormal total error score and maximal error in the red green axis (Fig. 2). Her visual fields were normal, as were the visual evoked responses from each eye. 


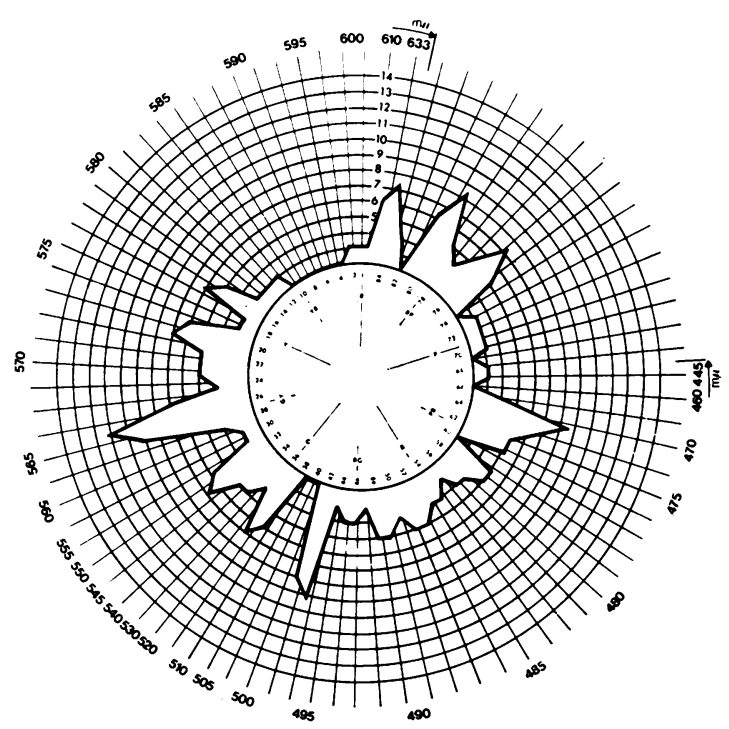

Fig. 2 Case $\mathrm{II}_{2}$, a definite carrier. FarnsworthMunsell 100 hue test showing increased total error score and a pattern of generalised poor colour discrimination.

\section{POTENTIAL CARRIERS}

Two of the daughters of $\mathrm{III}_{2}$ who are potential carriers were examined. Both were asymptomatic and had normal visual acuity, visual fields, and visual evoked responses. Colour testing, however, revealed abnormalities in both cases. Case $\mathrm{IV}_{3}$ had an abnormal total error score on the F-M test with a pattern of generalised poor colour discrimination. For logistic reasons she could not be examined with the anomaloscope. Case IV $_{5}$ though having a total error score on the FM test within normal limits was shown to have a clear red-green axis on the chart (Fig. 3). Her ability to match red and green on the anomaloscope was normal with an AQ of 1.0. Cases $I V_{6}$ and $I V_{8}$, who were reported as having no visual symptoms, were not available for study.

\section{OTHER ASYMPTOMATIC INDIVIDUALS}

The 5 children (cases $V_{3}-V_{7}$, aged 17-8 years) of one of the affected males (case $\mathrm{IV}_{4}$ ) were all examined and found to have normal visual acuities, colour vision, visual fields, and VERs. Case $V_{7}$ was too young to co-operate fully with the anomaloscope and F-M tests. Their normal colour tests as exemplified in Fig. 4 were in striking contrast to the abnormalities found in cases $V_{1}$ and $V_{2}$, who were the sons of $\mathrm{IV}_{3}$ and at risk of developing the disease. Both these cases had abnormalities on the F-M test with maximum errors in the red green axis (Figs. 5 and 6) and a green-deficient mismatch on the anomaloscope. In addition case $V_{2}$ had an

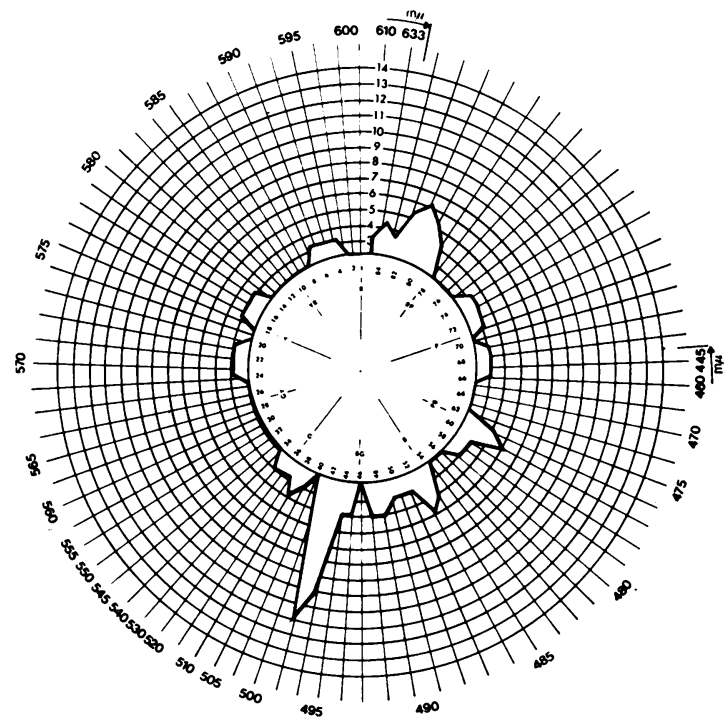

Fig. 3 Case $I V_{5}$, a potential carrier. FarnsworthMunsell 100 hue test with normal total error score but with maximal error in the red-green axis.

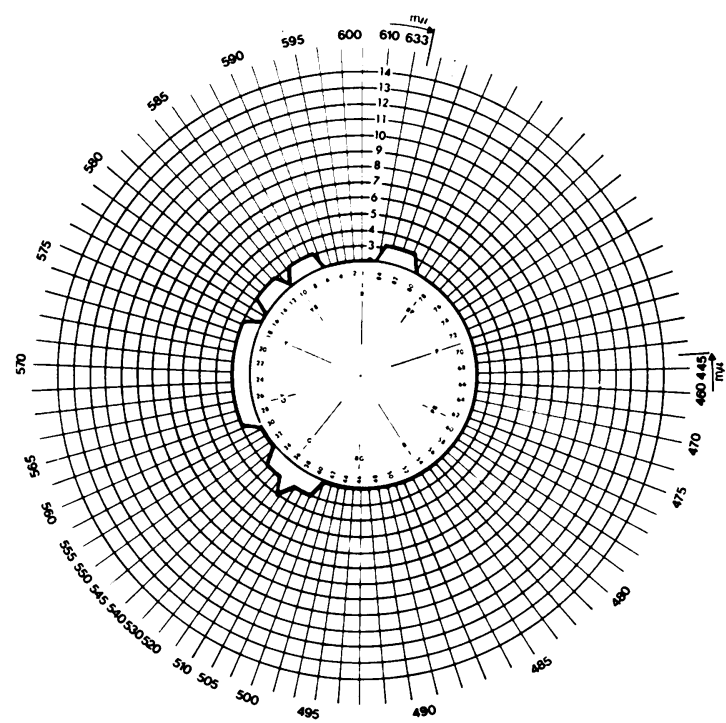

Fig. 4 Case $V_{4}$. Normal Farnsworth-Munsell 100 hue test.

abnormal VER with symmetrically delayed P2 latencies outside the normal range (P2 latency 136 $\mathrm{ms}$ in each eye; normal range 90-131 ms). The ophthalmoscopic appearance in each case was considered normal.

The 3 children (cases $V_{8}, V_{9}, V_{11}$, ages 17-12 years) of case $I_{5}$ were also found to have abnormal colour vision on the F-M test, with increased error 


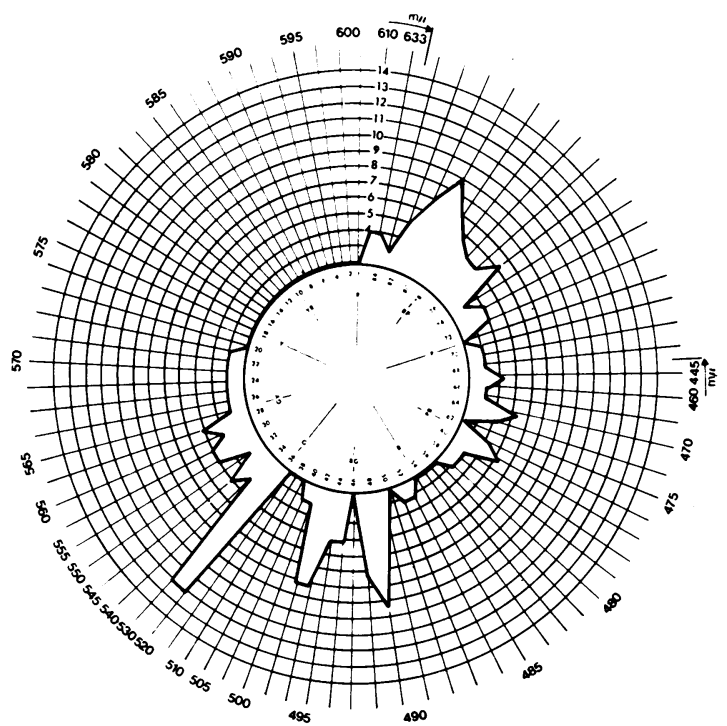

Fig. 5 Case $V_{1}$. Farnsworth-Munsell 100 hue test demonstrating increased total error score with maximal error in the red-green axis.

scores in each instance and a pattern of generalised poor colour discrimation (Fig. 7). The AQ of 1.247 in case $\mathrm{V}_{8}$ was abnormal, showing a green deficient match. The youngest daughter (case $V_{11}$ ) had bilateral temporal disc pallor, while the ophthalmoscopic appearances in her siblings were normal. The visual fields and VERs were normal in each case.

Case $\mathrm{IV}_{7}$, who was an unaffected male, and his 2 children (ages 6 and 9 years) had normal ophthalmoscopic appearances and VERs, but the children were too young to co-operate fully with the F-M and anomaloscope tests.

\section{Discussion}

SYMPTOMATIC INDIVIDUALS

The clinical neuro-ophthalmological and VER findings in the 2 affected patients reflect the state of advanced optic atrophy with markedly decreased visual acuities, flat unrecognisable VERs, central scotomata, and dyschromatopsia. The onset and progression of visual failure in these 2 cases is typical of Leber's optic neuropathy, and the appearance of the disc recorded at the time of onset of the symptoms is similar to that reported by others in the acute phase of the disease. ${ }^{14}{ }^{15}$

\section{ASYMPTOMATIC INDIVIDUALS}

In keeping with the expected pattern of genetic transmission no abnormalities were detected in

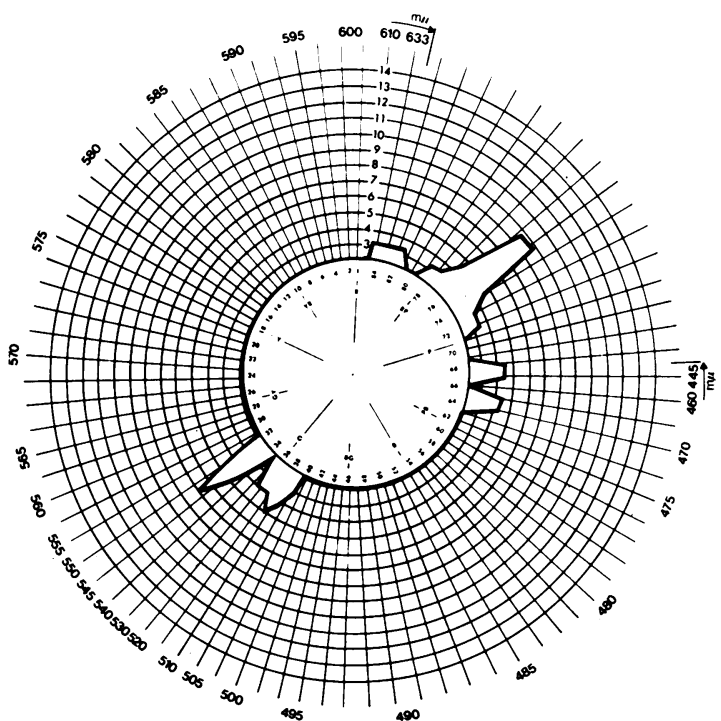

Fig. 6 Case $V_{2}$. Farnsworth-Munsell 100 hue test with normal total error score but with maximal error in the red-green axis.

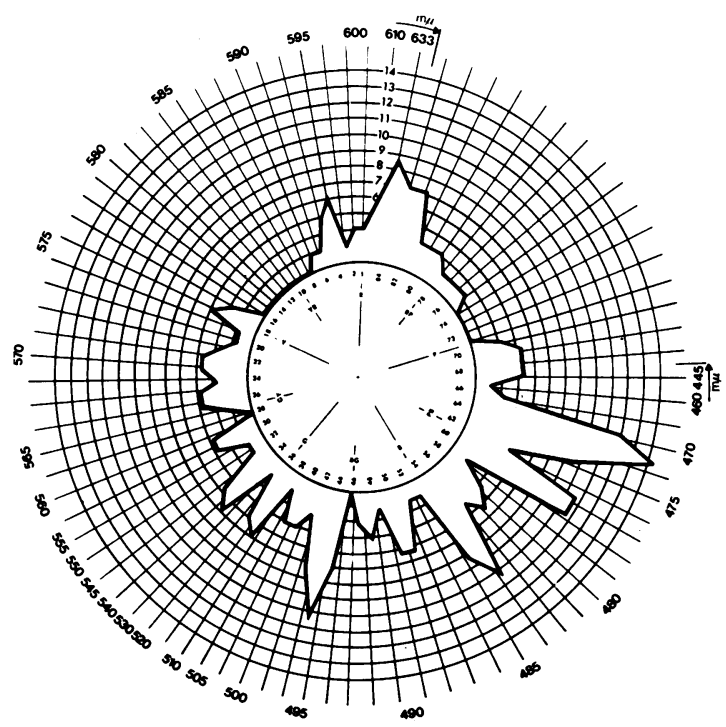

Fig. 7 Case $V_{8}$. Abnormal Farnsworth-Munsell 100 hue test with increased total error score and a pattern of generalised poor discrimination.

children of either affected or unaffected males in this pedigree. In contrast, however, abnormalities of colour vision, disc appearances, and/or VER in some asymptomatic potential or obligate female carriers and males at risk suggest that carrier detection and preclinical diagnosis is possible in 
Leber's optic neuropathy. The significance of increased retinal small vessel tortuosity observed in case $\mathrm{III}_{2}$, an obligate female carrier, is uncertain but has been noted previously in clinically affected patients $^{1415}$ and in some asymptomatic family members. ${ }^{10}$ It has been suggested that this increased tortuosity of small blood vessels is a separately inherited trait, ${ }^{16}$ but this requires further study. The assessment of temporal pallor of the optic discs is notoriously unreliable. The disc appearance of temporal pallor in case $\mathrm{IV}_{11}$ was noted by 2 independent clinicians, and this, together with the abnormal colour vision, to the best of our knowledge, represents the youngest asymptomatic member of a Leber's family to show neuro-ophthalmological abnormalities.

The abnormalities noted on colour testing require further analysis. Ishihara pseudoisochromatic plates provide a rapid method of detecting congenital colour deficiency but are less sensitive in determining acquired dyschromatopsia than tests such as the F-M 100 hue test. ${ }^{1217}$ Impairment of colour vision is a sensitive index of damage to the optic nerve, ${ }^{18}$ and recent studies have emphasised the accuracy of the F-M 100 hue test in detecting acquired colour vision defects in optic nerve disease. ${ }^{17}{ }^{19}$ The greater sensitivity of the F-M hue test is evident in this study. Of the 6 asymptomatic patients who had total error scores outside the normal range for their respective ages only 2 made mistakes on reading the Ishihara plates (cases $\mathrm{III}_{2}$ and $\mathrm{V}_{1}$ ).

The nature of the defective colour discrimination is of interest. In those patients in whom a confusion axis is recognisable on the polar co-ordinate diagram of the F-M 100 hue test, the axis is noted to lie in the red green plane. Acquired red-green deficiency has been noted in most diseases of the optic nerve, including Leber's optic neuropathy, and is characterised by a deutan-like discrimination defect. ${ }^{12}$ The abnormalities on the F-M $\mathbf{1 0 0}$ hue test were further confirmed by the anomaloscope, which tests the patient's ability to achieve Rayleigh's match. This match was noted to be deuteranomalous (green deficient) in all the patients with abnormal total error scores in the F-M test. In addition 1 patient $\left(V_{2}\right)$ who had a normal error score but a clear redgreen axis on the 100 hue test had a green-deficient match on the anomaloscope. These findings correspond to the deuteranomalous match of acquired red-green deficiency occurring with diseases of the optic nerve. ${ }^{12}$

The finding of a red-green axis on the F-M 100 hue test with a normal anomaly quotient is difficult to interpret in case $I V_{5}$, a potential carrier. The findings of abnormalities in all her children suggest that she is a detectable carrier of Leber's optic neuropathy. The significance of the abnormalities in her children will have to be clarified with the passage of time. Her son (case $V_{9}$ ) is clearly at risk for developing the disease, while his sisters, though at risk for developing the disease, are more likely to remain asymptomatic carriers.

The finding of symmetrically delayed VER P2 latencies in a young male at risk (case $\mathrm{V}_{2}$ ) suggests presymptomatic or early optic neuropathy. Similarly his brother, case $V_{1}$, although having normal VERs, must be placed in the high risk category in view of his abnormal colour discrimination. The abnormalities of colour vision noted in their mother, a potential carrier, further increase their risk of developing the disease. The predictive value of these investigations will have to be confirmed over the following few years, when these patients are likely to become symptomatic.

The finding in the present study of neuro-ophthalmological abnormalities in the daughters of female carriers in this family but not in the offspring of affected and unaffected males supports Seedorf's estimate $^{20}$ of a high carrier rate approaching $100 \%$ in daughters of carriers of this disease.

Although there is no conclusive proof of a metabolic viral or toxic cause for Leber's optic neuropathy, reports have suggested a defect in cyanide metabolism in this disorder. ${ }^{21}$ The detection of presymptomatic cases of Leber's optic neuropathy naturally raises the question of prophylactic treatment. No treatment has yet been shown to be effective in symptomatic cases of this disorder. Nikoskelainen et al. ${ }^{15}$ unsuccessfully treated 2 affected brothers in the early phases of the disease with prednisone and hydroxycobalamin. In view of the suspected defect in cyanide metabolism in some of these cases we think it advisable to give the 2 presymptomatic patients in our study high doses of hydroxycobalamin. This treatment is without side effect and appears to be the only therapeutic option available at this stage of the disease.

Our findings of neuro-ophthalmic abnormalities in some asymptomatic members of a family with Leber's optic neuropathy support those of a previous study ${ }^{10}$ and indicate that acquired dyschromatopsia, best detected by the F-M 100 hue test, may be the only detectable sign of optic nerve dysfunction. The predictive value of these neuro-ophthalmological abnormalities will, however, have to be confirmed by serial examinations over the next few years.

\section{References}

1 Leber $\mathrm{T}$. Über hereditaire und congenitalangelegte schnervenheiden. Albrecht von Graefes Arch Klin Ophthalmol 1871 ; 2: 249-91.

2 Waardenburg PJ. Some remarks on the clinical and 
genetic puzzle of Leber's optic neuritis. J Hum Genet $1969 ; 17$ : 479-96.

3 Seedorf T. Leber's disease. Acta Ophthalmol (Kbh) 1969; 47: 813-21.

4 Went LN. Leber disease and variants. In: Vinken PJ, Bruyn GW, eds. Handbook of Clinical Neurology. New York: American Elsevier Press, 1972: 13: 94-110.

5 Wallace DC. A new manifestation of Leber's disease and a new explanation for the agency responsible for its unusual pattern of inheritance. Brain 1970; 93: 121-32.

6 Erikson RP. Leber's optic atrophy, a possible example of maternal inheritance. Am J Hum Genet 1972; 24: 348-9.

7 Imai Y, Moriwaki D. A probable case of cytoplasmic inheritance in man; a critique of Leber's disease. J Genet 1936; 33: 163-7.

8 Colenbrander MC. Observations on the heredity of Leber's disease. Ophthalmologica 1962; 144: 446-50.

9 Harper PS. Mendelian inheritance or transmissible agent? The lesson of kuru and the Australia antigen. J Med Genet 1977; 14: 389-98.

10 Carroll WM, Mastaglia FL. Leber's optic neuropathy. A clinical and evoked potential study of affected and asymptomatic members of a six generation family. Brain 1979; 102: 559-80.

11 Farnsworth D. The Farnsworth-Munsell 100 hue test for the examination of color discrimination. Baltimore: Munsell Color Co. Inc. 1957: 2-7.
12 Verreist G. Further studies on acquired deficiency of color discrimination. J Opt Soc Am 1963; 53: 185-95.

13 Arden GB, Faulkner DJ, Mair C. A versatile television pattern generator for visual evoked potentials. In: Desmedt JE, ed. Visual Evoked Responses in Man: New Developments. Oxford: Clarendon Press, 1977.

14 Smith JL, Hoyt WF, Susac JO. Ocular fundus in acute Leber optic neuropathy. Arch Ophthalmol 1973; 90: 349-54.

15 Nikoskelainen E, Sogg RL, Rosenthal AR, Friberg TR, Dorfman LJ. The early phase in Leber hereditary optic atrophy. Arch Ophthalmol 1977; 95: 969-78.

16 Rogers JA. Leber's disease. Aust J Ophthalmol 1977; 5: 111-9.

17 Trusiewicz D. Farnsworth 100 hue test in diagnosis of ethambutol induced damage to optic nerve. Ophthalmologica 1975; 171: 425-31.

18 Walsh FB, Hoyt WF. Clinical Neuro-ophthalmology. 3rd ed. Baltimore: Williams and Wilkins, 1969: $1: 870$.

19 Griffin JF, Wray SH. Acquired color vision defects in retrobulbar neuritis. Am J Ophthalmol 1978; 86: 193-201.

20 Seedorf T. Leber's disease. Acta Ophthalmol (Kbh) 1970 ; 48: 187-213

21 Wilson J. Leber's hereditary optic atrophy: a possible defect of cyanide metabolism. Clin Sci Molec Med 1963; 29: 505-15. 